\title{
Pasado, prestigio y relaciones familiares. Elite e historiadores en Santa Fe, Argentina
}

\author{
Mariela Coudannes Aguirre - Universidad Nacional del Litoral ${ }^{1}$
}

\section{Resumen}

El presente trabajo estudia las relaciones entre historiadores y elite política en Santa Fe, Argentina, a mediados de la década de 1930. De datos relevados en artículos periodísticos de la época surge que estaban vinculados por matrimonio. Las relaciones familiares se tornaron vitales cuando Manuel María de Iriondo llegó al gobierno provincial y se propuso restaurar un gobierno de los "mejores". Este proyecto político condicionó la escritura de la historia y algunos de los principales miembros de la recientemente creada Junta de Estudios Históricos ocuparon el rol de intelectuales orgánicos dotando de prestigio a las principales familias de la red. El pasado fue un factor de cohesión interna para la elite política y una fuente de legitimación de su dominación sobre la sociedad santafesina.

Palabras clave: historiadores, matrimonio, elite, poder.

\begin{abstract}
The present work studies the relations between historians and political elite in Santa Fe, Argentina, in the middle of the decade of 1930. From data relieved in journalistic articles of the epoch arises that they were linked by marriage. The family relations became vital when Manuel María of I riondo arrived to provincial government and was proposed to restore a government of the "better". This political project conditioned the writing of the history and some of the main members of the recently created Junta de Estudios Históricos occupied the role of organic intellectuals endowing of prestige to the main families of the network. The past was a factor of internal cohesion for the political elite and a source of recognition of its domination on the society of Santa Fe.
\end{abstract}

Key words: historians, marriage, elite, power.

El presente trabajo se encuadra en los desarrollos teóricos que ven en las redes sociales un factor constitutivo principal de las sociedades ${ }^{2}$, y el profuso número de estudios empíricos que la aplican, la mayoría sobre temas de economía, comercio, familia, demografía, migraciones, geografía y cultura en los siglos XIX y XX. No se refiere a las redes como una modalidad organizativa de la sociedad civil de carácter horizontal y por lo tanto democratizante, sino su relación con la construcción de poder $^{3}$.

\footnotetext{
${ }^{1}$ Enviar correspondencia a: macoudan@fhuc.unl.edu.ar

2 Mann, Michael (1991). Las fuentes del poder social I. Madrid: Alianza. Allí se plantea que "Las sociedades están constituidas por múltiples redes socioespaciales de poder que se superponen y se intersectan", p. 14.

${ }^{3}$ Nos referimos al "parentesco como lógica de construcción del poder político", ver por ejemplo Falleti, Tulia. y Sislian, F. (1997). Dominación política, redes familiares y clientelismo. Buenos Aires: GEU.
} 
Luego de una conceptualización general, se aborda el análisis de un caso concreto: la relación de los historiadores con la elite santafesina a mediados de la década de 1930. En el mejor de los casos, la historia de la historiografía ha identificado su pertenencia común a una misma elite, sin matices. Lo que proponemos es explorar condicionamientos y posibilidades concretas que pusieron en juego los historiadores, como sujetos activos en un contexto particular.

En el vasto panorama de los posibles usos públicos de la historia, se hace presente la "política de la historia", cuando la mirada del historiador se deja influir por intereses individuales o colectivos de aclarar la propia situación histórica. ${ }^{4}$ Esta idea nos llevó a indagar qué rol jugaban las relaciones familiares, cómo se entrelazaban sociedad y política.

\section{Pensar la sociedad en términos de relaciones y redes}

La teoría de las redes registra su origen en teorías antropológicas (estructural funcionalismo británico), psicológicas (teoría de la Gestalt), sociológicas (estructural funcionalismo norteamericano, sociometría) y matemáticas, registrando su principal crecimiento en la década del setenta. Entonces, se producen cruces con las teorías del intercambio y la elección racional. Los estudios se han realizado sobre objetos a pequeña y gran escala, sobre relaciones de poder y autoridad pero también sobre familia, parentesco, afinidad y amistad, etc. Las redes sociales han sido definidas como "un conjunto bien delimitado de actores -individuos, grupos, organizaciones, comunidades, sociedades globales, etc.- vinculados unos a otros a través de una relación o un conjunto de relaciones sociales. ${ }^{5}$ El conjunto de teorías, conceptos y métodos (muchos de ellos diferentes entre sí) que confluyen en el análisis de las redes es Ilamado por Barry Wellman "paradigma analítico estructural"6 y está siendo aplicado en numerosas disciplinas, no sólo las mencionadas en su origen, sino también la ciencia política, la economía, la física, la biología y la informática, entre otras. En el campo de la historia su incorporación responde a una nueva historia social de inspiración microhistórica. Otros plantean que más que un

\footnotetext{
${ }^{4}$ Habermas distingue un "legítimo uso público de la historia" - aquel que diferencia entre la perspectiva del observador y la del participante- de la "política de la historia", cuando la mirada del historiador se deja influir por intereses individuales o colectivos de aclarar la propia situación histórica. En Habermas, Jürgen (2000). La constelación postnacional. Ensayos políticos. Barcelona: Paidós, p. 47.

${ }^{5}$ Lozares Colinas, Carlos (1996). “La teoría de las redes sociales”. Papers, № 48, Universidad Autónoma de Barcelona.

${ }^{6}$ Wellman, Barry (2000). "El análisis estructural: del método y la metáfora a la teoría y a la sustancia". Revista Política y Sociedad, № 33, Universidad Complutense de Madrid.
} 
paradigma se trata de un conjunto de técnicas con una perspectiva metodológica compartida.

Como es bien sabido, la utilización del concepto de red social implica incorporar el punto de vista de los individuos, pensar la sociedad en términos de vínculos personales que canalizan oportunidades y recursos, decisiones y estrategias en función de intereses individuales, familiares y grupales. El individuo tiene determinadas oportunidades y limitaciones en función de su pertenencia a esa estructura. Es una visión de la práctica social centrada en la interacción que constituye lo social. Los sujetos quedan identificados por su posición en la trama de relaciones:

La raza, la edad, el sexo, la categoría social importan mucho menos en la teoría de redes que las formas de las relaciones, mantenibles o mantenidas. (...) Los modelos de redes identifican la estructura social, económica, política, etc., como pautas constantes de relaciones entre actores (...)

... las acciones son consideradas en la medida que expresan una(s) propiedad(es) emergentes de la conexión o ligazón entre unidades de observación. (...) En este sentido, no es suficiente, p. e., con afirmar que la gente de status alto tiene más poder que la gente de bajo prestigio. De lo que hay que dar cuenta o explicar es de cómo los modelos o pautas relacionales crean diferencias de poder, estatus o prestigio entre la gente. (...) Los datos relacionales expresan contactos, transacciones, lazos, conexiones, vínculos, servicios dados o recibidos, comunicaciones entre grupos (...) la estructura del sistema se modifica conforme a las pautas cambiantes de la coalición y el conflicto ${ }^{7}$.

La lucha por los recursos en una estructura explicaría la aceptación de ciertas normas (cuando el sujeto sabe que está sometido a la presión de los demás implicados en la construcción social de esa red), y éstas serían un efecto y no una causa. Pertenecer a una red proporciona una serie de bienes y servicios, que en algún momento se tendrá que devolver si se quiere seguir perteneciendo... Las obligaciones recíprocas son particularmente fuertes en las relaciones de parentesco y le otorgan una marcada estabilidad a la red. Al mismo tiempo los lazos fuertes aquellos en los que se combinan duración, intensidad emocional, confianza mutua y servicios recíprocos-, aislan o "alienan" los individuos, impiden su integración en un orden social más amplio ${ }^{8}$.

\footnotetext{
${ }^{7}$ Lozares Colina, Carlos (1996). Ob. Cit., pp. 103-126.

8 Granovetter, Mark (2000). “La fuerza de los vínculos débiles”. Revista Política y Sociedad, № 33, Universidad Complutense de Madrid, p. 2.
} 
En el análisis sociológico de las redes se diferencia entre contenido y forma. El contenido hace referencia a la "sustancia relacional" - afecto, información, dinero, etc.- que fluye en las relaciones. Estas pueden ser formales (institucionales/ regladas) o informales; permanentes o pasajeras; en proceso o consumadas; direccionales o no; superficiales o profundas; conscientes o inconscientes. La forma de la red refiere a las propiedades de la configuración global, al modelo o estructura de la red. Otra clasificación habla de relaciones de comunicación, transacción, instrumentales, sentimentales, de autoridad o poder, de parentesco o descendencia, que resulta compatible con varios de los tipos anteriores.

La heterogénea conceptualización en torno a las redes sociales ofrece un sinnúmero de conceptos de los que sólo utilizamos algunos (principio de cohesión subjetiva, principio de rango o grado, etc.) ya que nuestro interés no es reconstruir el conjunto de la sociedad santafesina para el período estudiado sino algunas de las tramas fundamentales que podrían explicar el tipo de relaciones que establecen algunos de los historiadores santafesinos con la elite política local y su contribución a la construcción de capital social (prestigio histórico) para los nodos centrales de la red de familias.

La definición de capital social ha incorporado aportes de Pierre Bourdieu pero también de la teoría del capital humano de Gary Becker, la teoría de los lazos débiles de Mark Granovetter y el trabajo de Ronald Burt sobre los agujeros estructurales. La distribución del capital social es desigual e influye en la posición de los nodos en la red.

\section{Historia, política y relaciones familiares...}

La primera vez que llamaron nuestra atención las relaciones fue al comprobar, gracias a los datos que ofrecía el catálogo de egresados del Colegio de la Inmaculada de Santa Fe, las vinculaciones familiares entre los historiadores santafesinos. Julio y José Luis Busaniche se emparentaban por vía materna con los Lassaga, Luis Alberto Candioti con los Cervera. Gastón Gori hace mención al doble aprendizaje de José Carmelo Busaniche como político e historiador en el seno de la familia materna De Iriondo:

Cumplía horarios como auxiliar del Ministerio de Instrucción Pública... y comenzaría al estar cerca del poder público, a comprender los entretelones de la política provincial, cuyos antecedentes conociera en el medio familiar donde comenzó a sentir la gravitación del pasado histórico de su provincia natal $y$, también en la vida de quienes compartieran con él su interés cercano a hombres destacados de la actividad política y cultural. 
... [J osé Carmelo Busaniche no podía escapar, aun si hubiera querido] a la realidad de vivir una educación de antigüedad tradicional que se ramifica en múltiples apellidos sobrevivientes con actividades públicas notorias. ¿Cómo podría José Carmelo no sentir su influencia educativa, él que tanto arraigaba su pensamiento en el pasado? ¿Cómo no imaginar que se hallaba a sí mismo mientras relataba hechos de hombres que directa o indirectamente lo ataban a su propia genealogía? ${ }^{9}$

Se decidió seguir las trayectorias de aquellas familias e individuos pertenecientes a la elite política santafesina, la "estirpe de administradores", cuyo principal beneficio provenía de los cargos en el estado y en menor medida de la hacienda, en un contexto de crisis económica y agotamiento del modelo agroexportador. Esto surge, por un lado, de la apreciación de Darío Macor sobre que esa elite política fue la principal favorecida en el período iriondista (1937-1941) y la evidencia empírica que proporcionan las fuentes. Enrique Saguier proporciona un listado de miembros de la elite política santafesina en el mismo período, empleada para seleccionar apellidos y explorar sus vinculaciones en las noticias sociales del periódico santafesino El Orden (1927-1955). El atributo relacional relevado fue el matrimonio.

En casi todas las sociedades el matrimonio es un método para ampliar el rango de cooperación social a través de relaciones que se generan entre las personas y sus parientes políticos (afines), cuya amistad y apoyo son, a veces, hasta más importantes que los que brindan los parientes consanguíneos. La unión de dos personas en matrimonio es un fenómeno social. Puesto que la nueva pareja llegará a convertirse en una unidad básica de producción y reproducción, con representación legal y religiosa, las familias involucradas tomarán las decisiones y pasos necesarios para garantizar el bienestar general, proteger sus intereses y evitar los conflictos. (...) Las reglas endogámicas prescriben que los matrimonios se restrinjan a grupos sociales particulares. Esta práctica permite resaltar la identidad común y la singularidad por oposición a los grupos vecinos con los que se desaconseja realizar uniones matrimoniales ${ }^{10}$.

Este estudio se limitó a indagar la "visibilidad" de ciertas familias en un medio periodístico que contribuía a formar la opinión pública santafesina, su mención en las crónicas sociales, sobre todo en ocasión de actos conmemorativos, en un período de diez años. Resulta imposible reconstruir todos los lazos a partir de esta fuente, pero lo que interesaba era observar qué las dotaba de "notabilidad". Si se aceptan las sugerencias de Diana Balmori en su análisis de las familias prominentes de América Latina colonial, la notabilidad se obtiene no tanto por la riqueza o el

\footnotetext{
${ }^{9}$ Gori, Gastón (1998). José Carmelo Busaniche. Municipalidad de la ciudad de Santa Fe, pp. 12, 13, 16, 17 y 24.

10 Casasola, Silvia (2003). “El núcleo de la élite colonial de Santiago de Guatemala: un bloqueo cohesivo". Araucaria, № 10, Sevilla.
} 
puesto político, sino por su pertenencia a ciertas redes familiares. La reconstrucción fue posible gracias a la mención, en la mayoría de los casos, de los apellidos materno y paterno del individuo (y a veces de un tercer apellido, si éste resulta lo suficientemente ilustre), de la pareja o del apellido de casada si las mujeres asistían solas a los eventos sociales.

Los datos obtenidos se volcaron a una Matriz de Modo 1, se trataron con el programa UCInet $6^{11}$ y se visualizaron con Netdraw. Triangulando con textos de los historiadores fue posible confirmar la existencia de familias primarias -aquellas que reunían la condición de notabilidad por algún atributo particular, en este caso, constituir una "estirpe de administradores" y un "pasado ilustre" que necesitaba ser renovado o rehabilitado-, que se distinguían de las familias secundarias, las que conseguían emparentar con las primarias, pasando a formar parte del bloque de poder y reforzando el dominio y legitimación de la red principal.

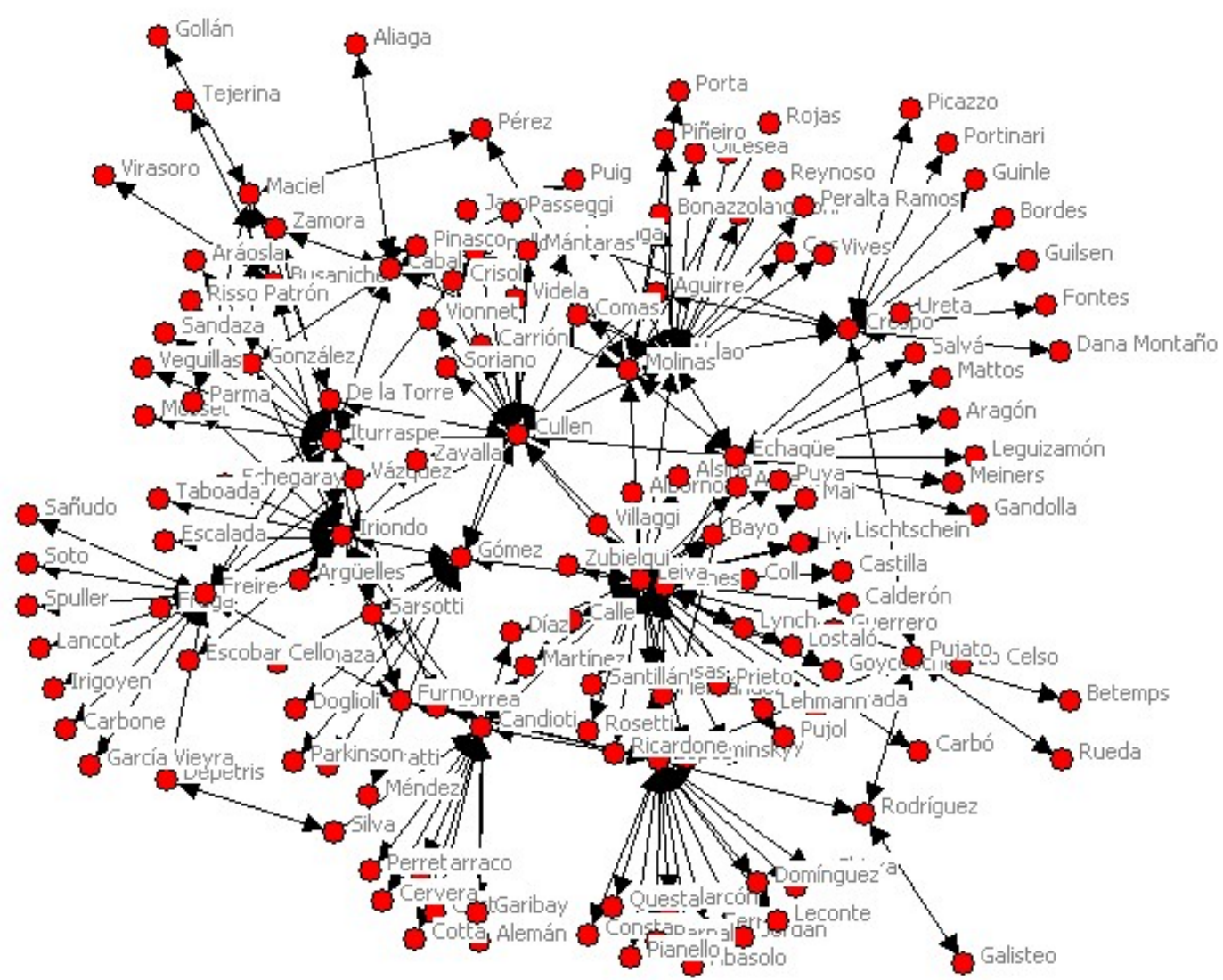

I lustración 1: Relaciones matrimoniales, por tanto recíprocas, entre familias, según datos proporcionados por El Orden, sobre 151 apellidos.

\footnotetext{
11 Borgatti, Steve, Everett, M.G. and Freeman, L.C. (2002). Ucinet for Windows: Software for Social Network Analysis. Harvard, MA: Analytic Technologies. (Versión de prueba gratuita disponible en http://www. analytictech.com/downloaduc6.htm)
} 


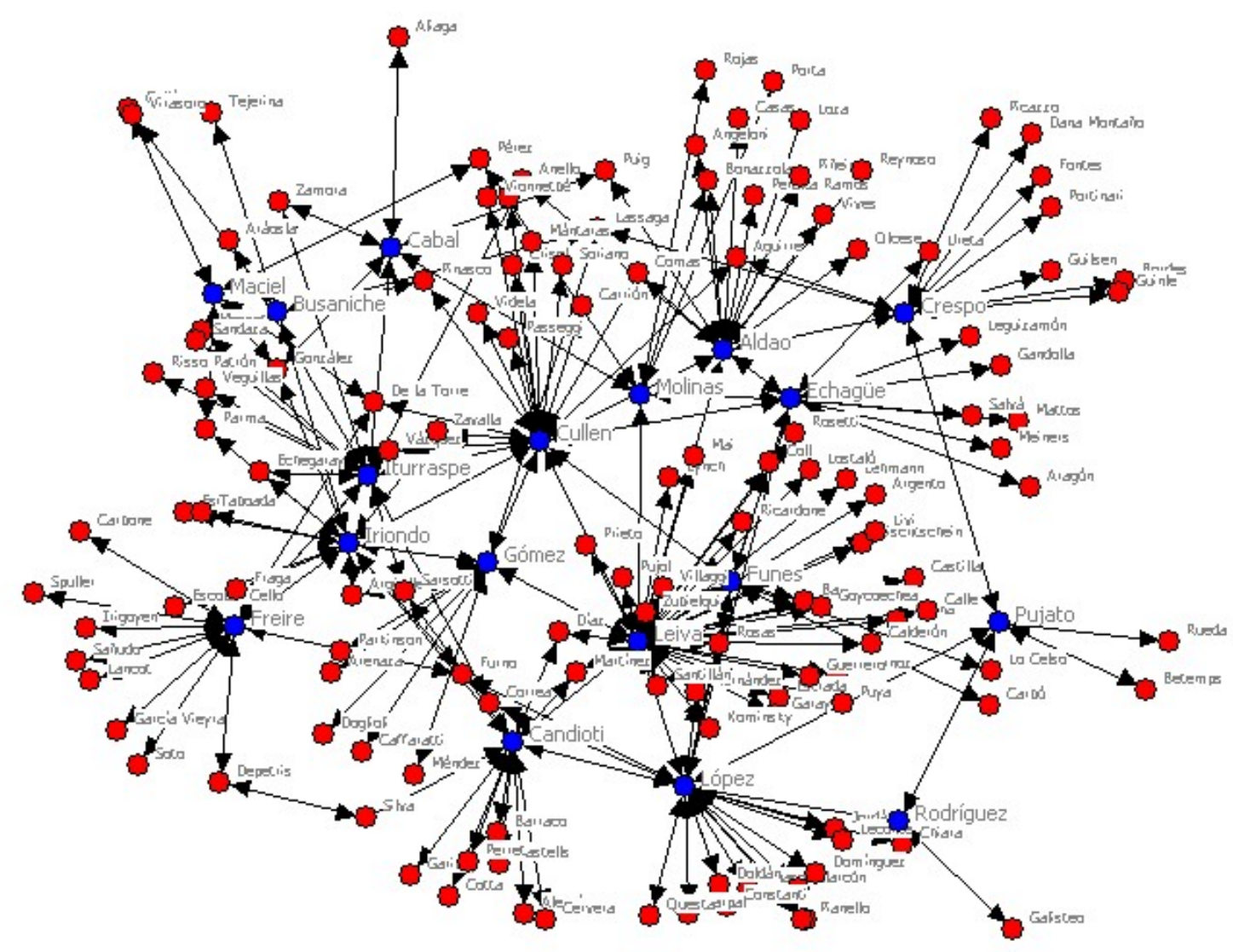

I lustración 2. En esta se destacan los bloques y puntos de corte: aquellos actores que en caso de ser eliminados, la estructura se divide en sistemas desconectados.

Los puntos de corte resultaron ser los apellidos: Aldao, Busaniche, Cabal, Candioti, Crespo, Cullen, Echagüe, Freyre, Funes, Gómez, Iriondo, Iturraspe, Leiva, López, Maciel, Molinas, Pujato, Rodríguez. Estos coinciden de una forma casi exacta con los apellidos de las señoras que componían la Sociedad de Beneficencia, la Comisión Pro-templo del Santísimo Sacramento y el Concejo Particular de las Damas Vicentinas. También coinciden con los dirigentes locales más destacados por los historiadores santafesinos.

\section{Los míos y los tuyos... legitimar a la red de familias}

¿Por qué era necesario legitimar? Hacia 1935 gobernaba la provincia de Santa Fe el Partido Demócrata Progresista, elegido por el voto popular. El gobierno nacional (Concordancia) no tenía un candidato que fuera mayoritariamente aceptado en la provincia; estaba desprestigiado por su acceso ilegítimo al poder, por el uso del fraude y por perjudicar los intereses locales. Entonces envió la intervención federal (1935) para forzar el cambio del partido en el poder, ante la perspectiva de unas elecciones que no lo favorecían. Su candidato, Manuel María de Iriondo (Antipersonalismo o UCR Santa Fe), si bien había nacido en la provincia y era 
miembro de una familia tradicional, no había ocupado cargos públicos en ella. Estudió y ocupó cargos públicos en Buenos Aires y luego a nivel nacional, en el gobierno de la Concordancia ${ }^{12}$. Algo similar sucedía con los Cullen que por añadidura sumaban un "desprestigio histórico".

El partido iriondista comprendía con claridad la importancia de controlar la conmemoración del pasado, incluso años antes de hacerse con el gobierno provincial. La tendencia a revalorizar los héroes locales encontró un terreno favorable con su llegada al poder. El iriondismo apuntaba a restaurar un gobierno de los "mejores" como factor de estabilización política para controlar la lucha partidaria; representaba a sectores tradicionales de la elite, aquellos que ocupaban los principales cargos en el estado. Por ejemplo, tras la intervención al gobierno demoprogresista accedieron a cargos Joaquín F. Rodríguez como Ministro de Gobierno, Justicia y Culto, y Juan Maciel, como Ministro de Hacienda y Obras Públicas.

Es interesante la sugerencia de Marta Casaús acerca de que en épocas de crisis económica de sociedades agroexportadoras, debilidad del Estado y de los partidos políticos, las familias de la elite diversifican su actividad u ocupan el Estado para sobrevivir y preservar su dominio. En el caso de la elite santafesina en la década del treinta se observa una marcada tendencia hacia la segunda estrategia. Para sobrevivir el sector de la elite en el poder deberá establecer acuerdos inter-elitarios y algún tipo de pacto con la sociedad civil, que asumían la forma de relaciones clientelares establecidas por un caudillo o líder carismático.

El 22 de marzo de 1933 se constituyó a iniciativa de Alfredo Bello una Comisión "Popular" con el propósito de homenajear "al esclarecido patriota, ex Gobernador de la Provincia de Santa Fe, Dr. Don Simón de Yriondo [padre de Manuel María], con motivo del próximo cincuentenario de su muerte". Integraban la comisión futuros miembros de la Junta de Estudios Históricos (Durán, Paredes, Barreto) y algunos partidarios del antipersonalismo. Durán y Paredes delegaron la escritura del libro en Barreto, todavía Director del Archivo Histórico. ${ }^{13}$ Sostenemos que esta producción historiográfica apuntó a una reconciliación del pasado de las familias centrales de la red, para apuntalar su estabilidad. Y con ello otorgar estabilidad a la estructura social. En palabras de Narciso Pizarro: “Es esta dimensión discursiva la

\footnotetext{
12 “Quién es quién. Biografías contemporáneas", El Orden, 23 de febrero de 1943.

${ }^{13}$ Barreto, Félix (1933). Dr. Simón de Iriondo. Santa Fe: El Litoral, pp. 3 y 5.
} 
que genera las categorías sociales, así como los criterios de pertenencia (y de la no pertenencia) a colectivos supra-nodales" ${ }^{14}$.

En su breve relato de los principales acontecimientos del accionar de Simón de Iriondo (apenas unas cincuenta páginas, el resto es transcripción de discursos, artículos periodísticos y otros documentos), Barreto exaltaba las condiciones morales y religiosas que provenían de la crianza familiar (destacaba que era nieto del primer gobernante constitucional, Francisco Candioti) y de la educación católica. Ellas eran fortaleza y serenidad para enfrentar los múltiples conflictos que se le iban a presentar, a lo que se sumaba la "fuerza de su dialéctica". Relataba los tempranos enfrentamientos (década de 1860) entre los Cullen y sus aliados liberales en el poder, y el Club del Pueblo. Aparecen también algunas referencias a las relaciones clientelares que se activaban cuando ocurría algún desastre social (por ejemplo inundaciones), la creación de comisiones de notables que organizaban la recaudación de fondos, las concesiones materiales a la Sociedad de Beneficencia, que fue creciendo en influencia, y la presencia personal en los barrios pobres. ${ }^{15}$

Barreto ponía también el acento en destacar cómo a pesar de las rivalidades políticas, De Iriondo fue dando cabida en su gobierno a los opositores, en distintas misiones que se les encomendaban, o beneficiándolos con contratos de colonización. En la nueva contienda electoral de 1878, se enfrentaron Ignacio Crespo y De Iriondo por la gobernación de la provincia. Si bien con resultados sangrientos, Barreto proporcionó una visión reconciliadora de los sectores en pugna:

Los dos candidatos contaban con las simpatías populares, desde el momento en que ambos profesaban los ideales democráticos que heredamos de nuestros antepasados gloriosos, y que el pueblo argentino sabrá mantener, aun a costa de su sangre que siempre fue fecunda... de su sangre que fertilizó en América la augusta concepción de la Libertad!... ${ }^{16}$

En 1936 se intensificó la campaña pero esta vez para conmemorar los cien años del nacimiento de Simón de Iriondo. Alegando la "justicia histórica" se impuso su nombre a distintos edificios públicos, a pedido de la Junta de Estudios Históricos, lo que fue rápidamente otorgado por el gobierno nacional. Adicionalmente, la Junta se dirigió al ministro de Justicia e Instrucción Pública de la Nación (el mismo Manuel

\footnotetext{
${ }^{14}$ Pizarro, Narciso (2000). “Presentación”. Revista Política y Sociedad, № 33, Universidad Complutense de Madrid.

${ }^{15}$ Barreto, Félix (1933). Ob. Cit., pp. 21 y 36.

${ }^{16}$ Idem, pp. 38, 39 y 44.
} 
María de Iriondo), para que las escuelas adhirieran a los homenajes mediante conferencias y clases alusivas por una semana ${ }^{17}$.

En el proceso de legitimación también se incluyó la relación con la familia de la esposa del candidato a gobernador. Poco tiempo atrás se había comenzado a gestionar una estatua dedicada a Rodolfo Freyre (ex gobernador y pariente cercano de la esposa de Manuel de Iriondo) en el 25 aniversario del puerto de Santa Fe, "motivo de progreso y orgullo" de la ciudad capital ${ }^{18}$. En la comisión presidida por Carlos Sarsotti (véase la vinculación de esta familia a los Gómez y a los Iriondo Ilustración 1 que reunía a autoridades y representantes del comercio, el agro y asociaciones profesionales santafesinas, participaron Manuel Cervera, Clementino Paredes y José María Funes ${ }^{19}$. El interventor nacional fue designado presidente honorario. $^{20}$

El acto conmemorativo se convirtió en político al inaugurarse ese mismo día la eclisa de una nueva vía que llegaba al puerto de cabotaje. Esto fue realizado por el gobierno de la intervención, duramente cuestionado por el diario El Orden. ${ }^{21}$ Merecen destacarse las palabras de Joaquín $F$. Rodríguez que se refierieron a Rodolfo Freyre como alguien que

...antes que Gobernante y estadista... fue un demócrata sincero que, sin ostentación de sus convicciones y sin alarde de su acción, supo acrecentar afectos con su consejo, entre sus amigos; y hacer germinar la gratitud, con su ayuda, entre los humildes (...) no buscó los cargos públicos para satisfacciones personales, que su honradez moral y material indiscutidas no se lo hubieran permitido, sino para cimentar el bienestar de sus conciudadanos. También su importante contribución al "progreso" de la provincia y el norte argentino ${ }^{22}$.

La personalidad de Salomé Freyre, esposa de Iriondo, también era resaltada recuperando una antigua nota que destacaba su acción caritativa durante la gran inundación del año 1905, su condición de mujer reconocida por la "alta sociedad" porteña pero al mismo una mujer de su hogar, buena y desinteresada. ${ }^{23}$ Se sumó

\footnotetext{
17 “El próximo homenaje a Don Simón de Iriondo. Sesionó la Junta de Estudios Históricos. Medio millón de pesos pedidos", El Orden, 4 de octubre de 1936.

18 "A propósito de un proyectado monumento", El Orden, 25 de diciembre de 1935.

19 “Organizan el homenaje al Doctor Rodolfo Freyre. Será recordada su memoria con motivo del 25 aniversario del Puerto", El Orden, 29 de noviembre de 1935.

20 “Un monumento se erigirá en memoria del Dr. R. Freyre", El Orden, 7 de diciembre de 1935.

21 "Con brillo se realizó el homenaje a Freyre", El Orden, 3 de enero de 1936.

22 “Ecos del homenaje al Dr. Rodolfo Freyre", El Orden, 4 de enero de 1936.

23 "Hace treinta años una dama santafecina dejaba huellas de su cariño por el pueblo", El Orden, 23 de enero de 1936.
} 
al reparto de juguetes en plena campaña electoral de su marido a través de la red de comités. También el ambiente familiar en su estancia "Las Mercedes" donde "el prestigio de su pasado, tan íntimamente unido a la historia de Santa Fe, se advierte allí en todas las cosas...", y por la presencia de un oratorio donde, según El Orden, se había demostrado innumerables veces el carácter piadoso de sus dueños ${ }^{24}$.

Al triunfar Manuel de Iriondo, El Orden destacaba que "Santa Fe inicia una nueva etapa. Recobra al mismo tiempo el goce de su autonomía". ${ }^{25}$ José Carmelo Busaniche, aficionado a la historia y sobrino del gobernador, fue nombrado secretario de la gobernación, aunque lo que se destaca que ello se debe a un reconocimiento de "sus brillantes dotes intelectuales y a su eficiente dinamismo" 26.

Finalizado el mandato de Iriondo, seguirán en el poder los hombres de la misma red de familias.

\section{Una historia fuertemente marcada por el proyecto político de la elite}

La Junta de Estudios Históricos obtuvo su actual denominación el 15 de junio de 1936. Sus primeros integrantes habían sido Manuel Cervera, Clementino Paredes, Ángel Caballero Martín, Salvador Dana Montaño, José María Funes, Julio A. Busaniche, Eduardo Carasa, Alfonso Durán y Félix Barreto. En 1936 se incorporaron Nicolás Fasolino, Rodolfo Reyna, Armando Antille y Nicanor Molinas.

A continuación, las conexiones entre algunos de los historiadores. Se calcularon los caminos más cortos con las herramientas del programa UCInet 6.

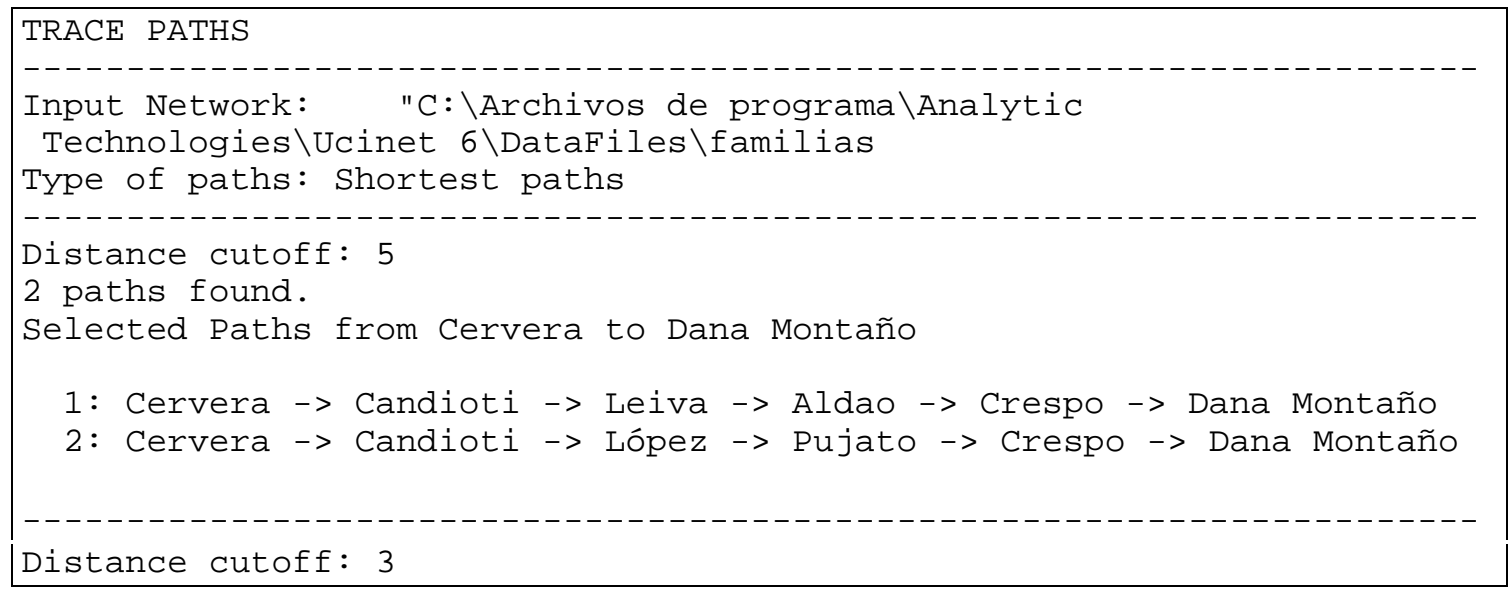

\footnotetext{
24 "Se realizó en Las Mercedes una ceremonia sencilla y de un gran sentido de evocación", El Orden, 12 de abril de 1936.

${ }^{25}$ El Orden, 10 de abril de 1937.

${ }^{26}$ Sr. Carmelo Busaniche, El Orden, 13 de abril de 1937.
} 


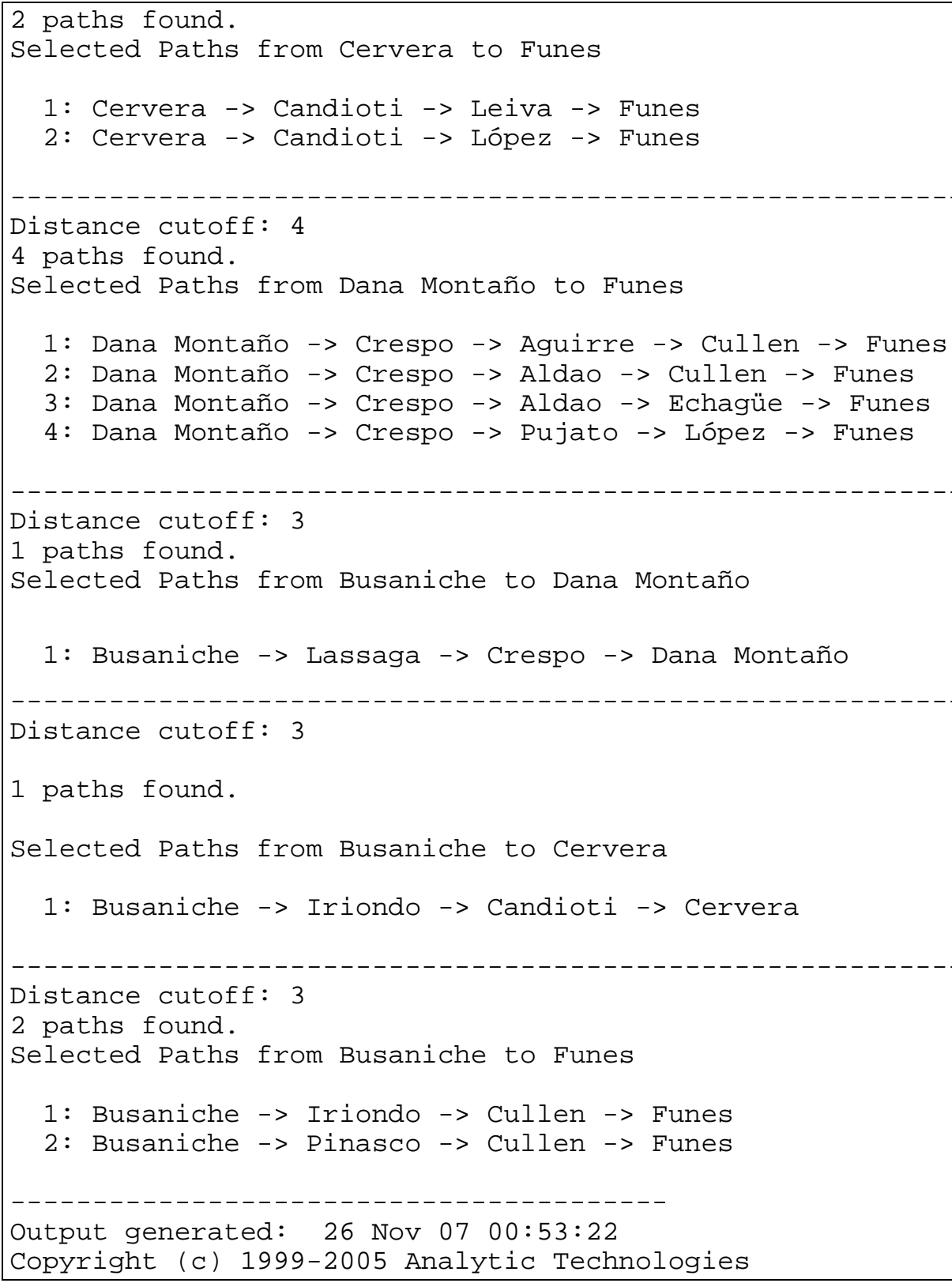

Cuadro 1. Los historiadores estaban estrechamente vinculados entre sí por los apellidos destacados como puntos de corte en la llustración 2.

Los miembros de la Junta buscaron involucrarse y opinar sobre todos aquellos aspectos de las políticas públicas que tuvieran relación con lo histórico y conmemorativo. De hacerse un "lugar bajo el sol” y obtener el apoyo oficial.

En ocasión de las Jornadas de conmemoración de los cien años del fallecimiento del ex gobernador Brigadier General Estanislao López (1938), las temáticas para el debate académico fueron propuestas por Salvador Dana Montaño. Dichos temas eran la personalidad del caudillo, su época, su obra nacional y provincial, y por 
último sus colaboradores. ${ }^{27}$ Su rectitud y su espíritu de diálogo eran cualidades tan importantes como la ilustración de los hombres que lo asesoraron. Por esto, si bien se pretendía reivindicar la figura de López, de caudillo a héroe nacional, también se expresaba el propósito de reconstruir a partir de los documentos un cuerpo de ideas que más que pertenecer a un hombre fueron un producto colectivo: "un ideario político determinado, orgánico, individualizable, capaz de constituir un cuerpo de doctrina." El premio "Ramón Lassaga"28 sería otorgado a quien mejor fundamentara este postulado. Por su parte, Manuel Cervera manifestaba la necesidad de reconocer la actuación de los antepasados, aquellos que podían mostrarse como ejemplos a seguir en el presente:

... Dar a los que fueron y sobresalieron, el mérito que les corresponde, o la reprobación justificada por sus actos; conocer el medio ambiente en el que actuaron; interiorizarse en todo cuanto pueda ser un ejemplo merecedor de aplauso, o un oprobio digno de censura; recordar lo bueno y noble de nuestros antepasados ${ }^{29} \ldots$

Algunos de los premios - medallas- otorgados a los que se consideraban los mejores trabajos fueron donados por nietos sanguíneos y políticos del Brigadier aclarando que lo hacían en memoria de sus antepasados ${ }^{30}$. Coincidiendo con esta perspectiva, el Gobernador expresó que López "supo rodearse de grandes asesores, dotados de altas calidades intelectuales y morales" ${ }^{31}$. Por su parte, el ministro de Gobierno, Severo Gómez, casado con una Cullen y presidente de la Sociedad Rural en los momentos previos a su desempeño público, expresó que:

...la voz autorizada de los historiadores que se habían congregado en esta capital han ratificado el pensamiento del Poder Ejecutivo y que el sistema de los pactos preexistentes han sido la base de la Constitución y la unidad nacional. En forma extensa y brillante... destacó los perfiles de la personalidad de López, haciendo interpretaciones relacionadas con la historia y la época en que actuó el Brigadier. Después de otras consideraciones habló del unitarismo y federalismo para recordar a los descendientes del Patriarca de la Federación ${ }^{32}$.

\footnotetext{
${ }^{27}$ Entre ellos figuraban: “Juan Francisco Seguí, José de Amenábar, Luis Aldao, Agustín Urtubey, Pedro Tomás de Larrechea, J osé Miguel Carreras, Cosme Maciel, Carlos María de Alvear, Francisco Seguí, Pedro Aldao, José Elías Galisteo, Domingo Cullen, Pascual Echagüe, Juan Pablo López, Domingo de Oro, etc., etc." En A. A. V. V. (1941). Jornadas de Estudios Históricos sobre el Brigadier General Estanislao López en el primer centenario de su muerte, 1838 - 15 de junio- 1938. Santa Fe, tomo 1, p. 7.

${ }^{28}$ Este grupo constituye como su principal referente historiográfico a Ramón Lassaga. En las Jornadas de Estudios Históricos sobre el Brigadier General Estanislao López, Salvador Dana Montaño hace referencia al Dr. Ramón J. Lassaga, como primer biógrafo de Estanislao López, obviando la referencia a los antecedentes de Pedro de Ángelis y Olegario V. Andrade.

${ }^{29}$ A. A. V. V. (1941). Ob. Cit., p. 22.

30 “Discernió el Jurado los premios a los trabajos sobre el General López", El Orden, 16 de junio de 1938.

31 “López sometió su gobierno a la norma jurídica. El gobernador de la provincia pronunció un hermoso discurso", El Orden, 16 de junio de 1938.

32 “El discurso del ministro de Gobierno", El Orden, 16 de junio de 1938.
} 
Al año siguiente de este gran despliegue oficial para restituir a la figura de López el lugar que se suponía merecía en el panteón de los héroes nacionales, su conmemoración había perdido fuerza. Mientras tanto, se había producido un vuelco significativo en la atención oficial e historiográfica hacia la reivindicación de uno de los "colaboradores" de López: Domingo Cullen. Fueron los Cullen, a la cabeza de una red de familias, los que capitalizaron los actos del año anterior. Tomás R. Cullen había sido el presidente de la Comisión oficial de homenaje de Buenos Aires y fue el encargado de pronunciar un discurso en nombre de los descendientes del Brigadier. El 13 y 14 de junio de ese mismo año habían sido publicados en El Orden y en El Litoral extensos recordatorios del natalicio del hijo de Domingo Cullen, también llamado Tomás:

... criado en un hogar en donde se rendía culto a las más ponderables virtudes y dotado de relevantes condiciones de caballero, don Tomás Cullen no tardó en señalarse como hombre público de prestigio, al que en momentos delicados de la vida de su provincia natal, habrían de confiársele funciones de responsabilidad... ${ }^{33}$

Su vida, estuvo estrechamente ligada a la vida de Santa Fe, y en las oportunidades en que fue llamado a actuar en la vida pública, siempre en momentos difíciles y a menudo angustiosos, pudo su prestigio de hombre de bien, ecuánime, justiciero y generoso, equilibrar las rencillas, llevando la serenidad a los espíritus, apagando los odios y haciendo olvidar las ofensas... ${ }^{34}$

... patricia figura que entronca con respetables hogares santafesinos..." Un periódico de Buenos Aires lo recordaba como el "Jefe de la tradicional familia, que se haya vinculada a la más alta sociedad de la culta Santa Fe (...) Nadie... dejará de recordar a la casa patriarcal siempre abierta al viajero, las costumbres sencillas, la franqueza de la hospitalidad, la cultura del trato, la sinceridad del ofrecimiento ${ }^{35}$.

Lo próximo era cuestionar la visión negativa que algunos sostenían contra el español Domingo Cullen y así legitimar a toda la red familiar, cuyos miembros principales apoyaban o participaban del gobierno de Iriondo. Colaborador estrecho de Estanislao López y su sucesor, Domingo Cullen había sido acusado por la historiografía de haber colaborado en el asesinato de Facundo Quiroga, y de tratar con agentes franceses en forma unilateral para levantar el bloqueo francés a la provincia de Santa Fe, desconociendo los pactos con Buenos Aires. También era visto como un advenedizo y un oportunista que había escalado posiciones

\footnotetext{
33 “Primer Centenario del nacimiento de Don Tomás Cullen", El Litoral, 13 de junio de 1938.

34 "A los 100 años del nacimiento de don Tomás Cullen. Una figura patricia del viejo Santa Fe", El Orden, 14 de junio de 1938.

35 “Notas del cronista”, El Orden, 14 de junio de 1938.
} 
aprovechando la falta de confianza de López en la dirigencia local. La provincia fue invadida por Juan Pablo López con apoyo de Buenos Aires y Cullen debió refugiarse en Santiago del Estero, tiempo después era fusilado por orden de Juan Manuel de Rosas.

Según las investigaciones de Ana María Cecchini de Dallo "cuyismo" y "Iopismo" constituyeron grupos políticos bien diferenciados a mediados del siglo XIX. El cuyismo se caracterizó por constituirse primordialmente a partir de relaciones familiares endogámicas, que se explican por las características de la sociedad santafesina, pequeña y expulsora de habitantes.

Esa cualidad del «cuyismo» le generó gran parte de sus enemigos políticos quienes no discrepaban con su labor gubernamental sino que se sentían marginados de ese núcleo basado en la sangre... (y denunciaban) el «círculo de familia» ${ }^{36}$.

Eran predominantemente hacendados y comerciantes, el grupo económico más importante de la provincia en esa etapa. Ocuparon importantes cargos en la administración provincial y nacional pero varios de ellos tuvieron que exiliarse durante el gobierno de Rosas, logrando retornar a lugares de importancia durante los gobiernos de Domingo Crespo y José María Cullen. Formarían varios años después el partido liberal.

Ambos grupos aceptaron subordinarse al poder federal de Urquiza, pero Juan Pablo López consiguió su apoyo para "derrocar" al cuyismo. Durante su gobierno estuvieron totalmente marginados de la administración provincial. En el trabajo de Cecchini el lopismo tiene una connotación negativa, asociada a supuestas características de su líder: "anarquía, indefinición política y variabilidad en las ideas", conspiración, deslealtad, escasa productividad económica ganadera, ausencia de carisma. Se desvincula al lopismo del posterior iriondismo:

Si bien muchos de los hombres que se reunían alrededor de López formaron parte posteriormente del partido que se integró en torno a Simón de Iriondo: el Club del Pueblo, no puede considerarse el Club del Pueblo como derivación del lopismo pues constituyó un grupo político nuevo, originado en la década 1860- 1870 a partir de la personalidad política de Simón de Iriondo ${ }^{37}$.

\footnotetext{
${ }^{36}$ Cecchini de Dallo, Ana (1992). Los grupos políticos en Santa Fe. Santa Fe: Ministerio de Educación y Cultura de la provincia de Santa Fe, pp. 71 a 74.

${ }^{37}$ Idem, pp. 75 y 76.
} 
Este es sólo un ejemplo de los conflictos que todavía eran recordados en la década del treinta. Volviendo a 1939, la conmemoración fue preparada cuidadosamente, se organizó una "Comisión popular de homenaje" y también fue invitado el historiador de la Universidad de Buenos Aires, Dr. Emilio Ravignani, que pronunció un discurso sobre la "personalidad" de Domingo Cullen en el Paraninfo de la Universidad Nacional del Litoral. Al igual que López, existía sumo interés en destacar su actuación en el campo político nacional. Los actos no se redujeron a la ciudad de Santa Fe, sino que también se realizaron en Rosario y San Nicolás, a donde se trasladaron los miembros de la Junta Manuel Cervera, Armando Antille y Salvador Dana Montaño. Se decretó suspensión de actividades por la tarde, se colocó una piedra conmemorativa (en esta oportunidad, José Carmelo Busaniche, subsecretario de Instrucción Pública estuvo a cargo del discurso oficial), se organizó el homenaje escolar y se publicaron reseñas históricas en El Litoral. Una de ellas, a cargo de Félix A. Chaparro, miembro de la filial Rosario de la Academia Nacional de la Historia, realizaba la operación de trasladar las virtudes de López a Cullen, de las que no cabía dudar precisamente por la relación de confianza, amistad y luego parentesco con el Brigadier.

En otro artículo, Leopoldo Kanner destacaba que “con él inicia López la organización administrativa de la provincia" ${ }^{38}$, sin duda un argumento muy apropiado para legitimar a una "estirpe" de administradores. En una nota ampliatoria sobre los descendientes presentes en los distintos actos se proporcionaba una extensa y detallada nómina de las familias emparentadas. ${ }^{39}$

En 1940 una comisión viajó a Montevideo para participar del homenaje que realizaron sus autoridades a Domingo Cullen. Consistió en la designación de una calle con su nombre y descubrimiento de una placa. El delegado del gobierno fue José Carmelo Busaniche y contó con la presencia de algunas autoridades nacionales, y funcionarios diplomáticos de otros países. Los descendientes presentes, encabezados por Tomás R. Cullen, eran pertenecientes a la red de familias que venimos siguiendo regularmente desde 1935. Sus pretensiones hegemónicas no se reducían a la provincia de Santa Fe. ${ }^{40}$

A continuación se grafica un recorte del grafo donde el nodo Cullen es el que registra el mayor número de lazos directos.

\footnotetext{
38 "Semblanza y muerte de Domingo Cullen", El Litoral, 21 de junio de 1939.

39 “Homenaje a D. Domingo Cullen”, El Litoral, 22 de junio de 1939.
} 


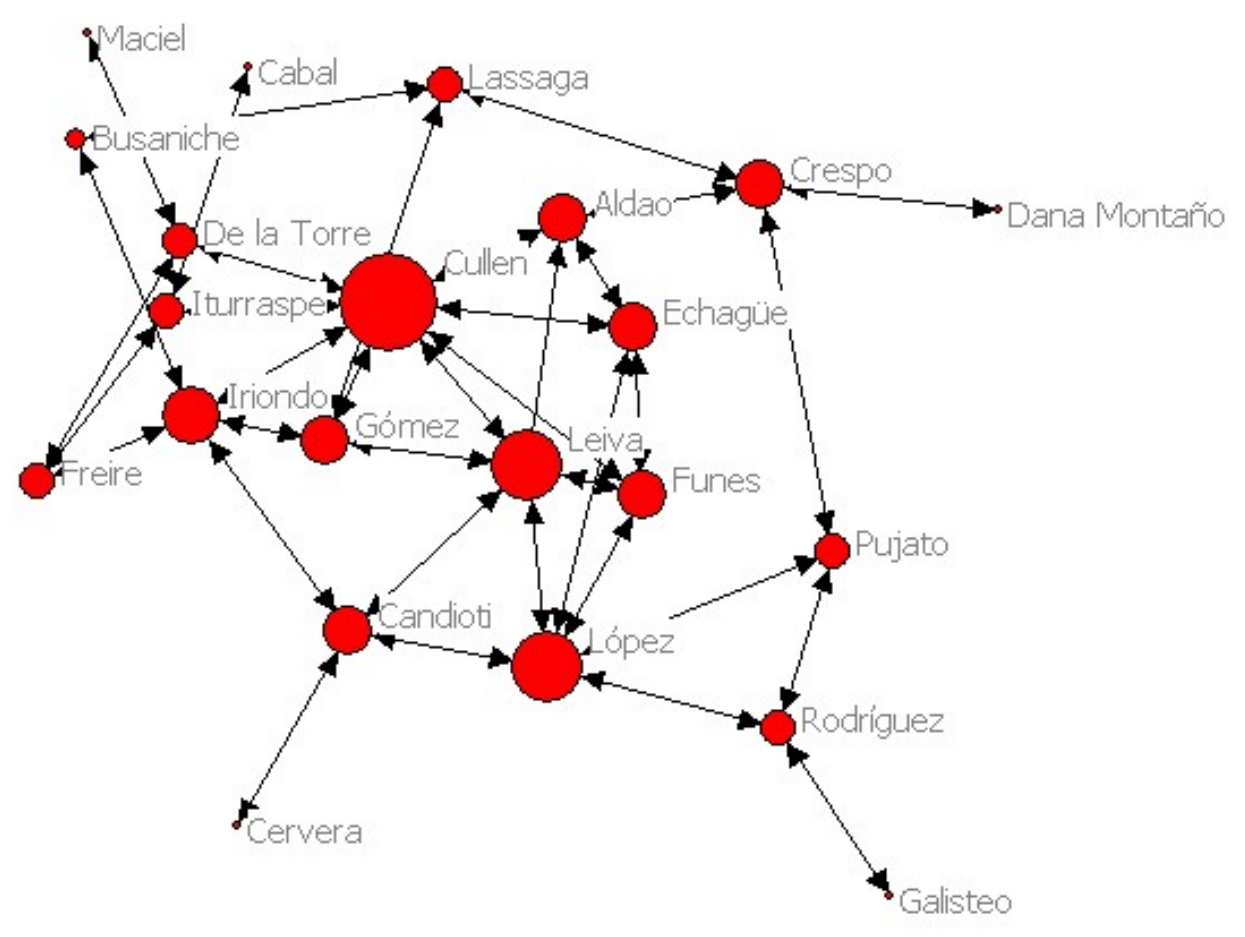

I lustración 3. Relaciones entre historiadores y los apellidos destacados en sus trabajos de divulgación historiográfica. Análisis según el principio de centralidad. Medida: grado.

\section{La producción historiográfica en torno a la figura de Domingo Cullen}

La vida y acción política de Domingo Cullen fueron tratadas en las obras de José Luis Busaniche ${ }^{41}$, Salvador Dana Montaño y Félix Chaparro, en el año 1939. Si bien todos aportaron a la empresa colectiva de legitimación de la familia Cullen, cumpliendo en mayor o menor medida su rol de intelectuales orgánicos ${ }^{42}$, aquí sólo analizaremos la de Salvador Dana Montaño.

Como la mayoría de los integrantes de la Junta de Estudios Históricos, Salvador Dana Montaño (1906-1992) egresó del Colegio Jesuita de la Inmaculada Concepción y obtuvo su título de abogado en la UNL, donde estuvo a cargo de la

\footnotetext{
40 “Homenaje a D. Cullen”, El Orden, 17 de marzo de 1940.

41 Nuevas comprobaciones sobre la misión Cullen, 1838 (1936), Domingo Cullen (con formato de divulgación, junio de 1939), Bloqueo francés de 1838 y la misión Cullen, Federalismo y Rosismo (1945), en forma de libro a partir de tres monografías publicadas anteriormente por la Universidad de Buenos Aires y la Universidad Nacional de La Plata entre 1934 y 1939.

42 Las alianzas matrimoniales y económicas (mayormente endogámicas), la participación en asociaciones políticas, religiosas, socioculturales y la formación de sus propios intelectuales aseguran unidad, homogeneidad y permanencia en el tiempo de las redes. Así lo afirma Casaús, Marta (1994). “La
} 
cátedra de Derecho Público. Ocupó distintos cargos en Juzgados, fue miembro de distintas Academias internacionales, juntas e institutos.

El libro "Domingo Cullen" era la impresión de una conferencia dictada en el Club del Progreso. Fue editada por la Universidad Nacional del Litoral y en la portada se presentaba a Dana Montaño con el único antecedente de "Miembro del Instituto Internacional de Historia Política y Constitucional (París)", lo que a todas luces resultaba suficiente para dotar de prestigio intelectual al autor. A continuación constaba una mención de obras publicadas, agrupadas en Historia (Jurídica y Política) y Derecho- Política.

En la introducción se recogían las palabras de Rodolfo Rivarola:

Conmemoramos, a un siglo de distancia, en el tiempo, la tragedia de un ilustre servidor del orden institucional, Don Domingo Cullen.

El sacrificio de su vida fue uno entre centenares de víctimas, en el ciclo rojo de la historia argentina. Honramos la memoria de la víctima sin reabrir el proceso del victimario. La Provincia de Santa Fe lo recuerda como si hubiere nacido en su suelo. Su descendencia justifica el título de gran ciudadano argentino, que corresponde a su antecesor. (...) En ella (Santa Fe) fundó su hogar y dio nombre a una descendencia que supo conservarlo con honor ${ }^{43}$.

Cuando se refería a Dana Montaño destacaba que, si bien joven, ya era un "ilustre coprovinciano", por su "intensa y vigorosa labor intelectual" y "serios escritos de exposición y crítica". Dana Montaña respondería haciendo alarde de modestia y que el único motivo de haber aceptado la invitación de la comisión de homenaje a Cullen era su profunda veneración por haber sido éste uno de los firmantes del Pacto Federal de $1831^{44}$.

Gracias al estudio de redes podemos saber que Salvador Dana Montaño estaba conectado a la red de familias del bloque dominante gracias a su matrimonio con Etelvina Crespo Fontes ${ }^{45}$, y que este fue uno de los verdaderos motivos para aceptar participar de la "movida Cullen", en momentos que uno de sus más fuertes representantes en el gobierno, Severo Gómez, estaba siendo fuertemente cuestionado por fraude electoral y malversación de fondos públicos, entre otros motivos. Ello evidencia las obligaciones que implicaba ser parte de la red.

pervivencia de las redes familiares en la configuración de la elite de poder centroamericana (El caso de la familia Díaz Durán)". Anuario de Estudios Centroamericanos, Vol. 20, № 2, Universidad de Costa Rica.

43 Dana Montaño, Salvador (1939). Domingo Cullen. Santa Fe y la organización nacional (1818- 1838). Santa Fe: UNL, pp. 7 a 9.

${ }^{44}$ Idem, pp. 9 y 11.

45 “Fue bendecida ayer la boda de la pareja Dana Montaño- Carrasco", El Orden, 2 de agosto de 1935. 


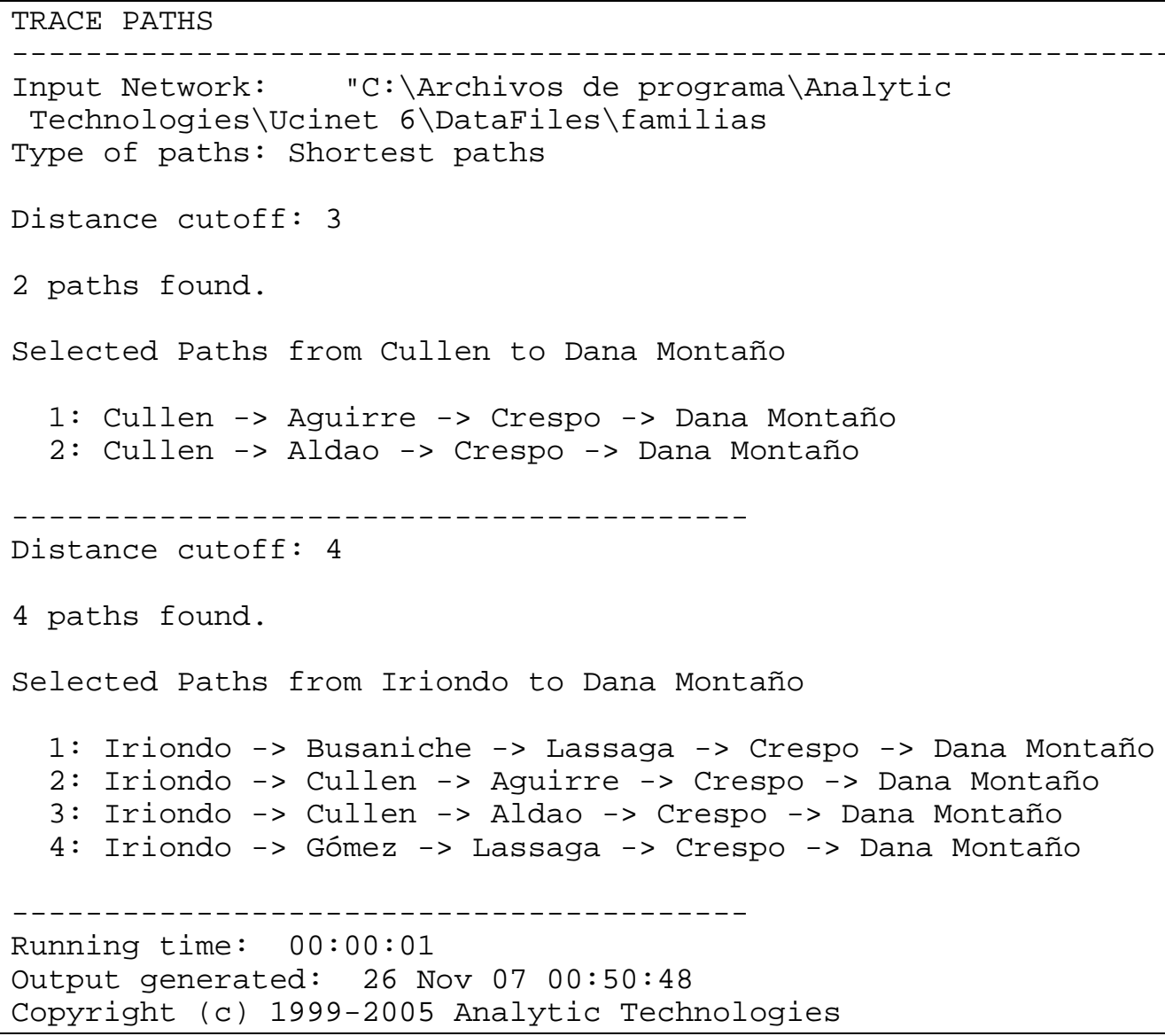

Cuadro 2: Distancia geodésica entre Dana Montaño/ Cullen y entre Dana Montaño/ I riondo.

Aun así, Dana Montaño intentaba borrar toda sospecha sobre su labor intelectual cuando afirmaba:

Equidistante de ambas tendencias, sin afinidades de partido o de apellido, sin prevenciones ni odios, heredados o contagiados, exclusivamente como hombre de estudio, creo con sinceridad hacer Historia objetiva ${ }^{46}$.

El hecho de recuperar la figura de Cullen tenía coherencia con su insistencia en las Jornadas de 1938 de identificar al grupo de colaboradores del General López (Vera, Maciel, Larrechea, Seguí y Amenábar) con los ideólogos de los planteos autonomistas de López:

Tuvo aquél una particularísima intuición acerca de las cualidades intelectuales y morales de sus colaboradores. Cuidaba, como una prenda de acierto personal, de la selección de sus secretarios, ministros y allegados, a quienes escogía con esmero de entre la flor y nata de sus contemporáneos. Demostraba con ello poseer una relevante condición de hombre político y de gobierno. (...) Podría citar muchos nombres, que se han repetido luego unidos a los apellidos tradicionales de Santa Fe, pero me bastará evocar uno

${ }^{46}$ Dana Montaño, Salvador (1939). Ob. Cit., p. 18. 
solo de ellos, como tipo representativo de los que fueron sus allegados, sus hombres de confianza, sus consejeros y sus auxiliares en las nobles y arduas tareas del gobierno de la época, a la vez, organizador y guerrero, militar y político, diplomático y civilizador.

Me refiero a Don Domingo Cullen, que no fue santafesino de nacimiento, como los Maziel, los Vera, los Pujato, los Crespo, los Galisteo, los de la Torre, los López, los de Larrachea, los Leiva, los Echagüe, los Aldao, los de Iriondo, los Cabal, los Lassaga, los Candioti y tantos más; que fue extranjero, como los primeros varones de aquellos ilustres apellidos, pero que habría de ser, a poco de llegar a nuestro suelo, cumpliendo una ley felicísima de adaptación a nuestras costumbres y a nuestras cosas, «ciudadano argentino por elección y servicios», como le llamó Mantilla ${ }^{47}$.

Argumentaba la nobleza de sangre de Domingo Cullen y no sólo eso, "su fidelidad religiosa y su vocación por los destinos trágicos" y la intuición de López al trabar relaciones políticas. Hacía hincapié en cómo estas se estrecharon por el matrimonio de Cullen:

Es indudable que su entronque con uno de los apellidos más distinguidos de la ciudad, al estrechar aun más los lazos que le unían al Gobernador, dio a Cullen la jerarquía social necesaria en el orden local, a que tenía derecho, por otra parte, por su noble prosapia. Y sus conocimientos, sus condiciones personales y la experiencia adquirida en los negocios públicos, como protagonista o como espectador inteligente le pusieron en el camino de las más espectables posiciones oficiales ${ }^{48}$.

Según Dana Montaño, la confianza de López se vio expresada en que en las negociaciones con las provincias, Cullen siempre era enviado al destino más difícil, llevando instrucciones expresas que no atentaban contra la soberanía nacional. Tanto López como Cullen habían servido a la causa federal, con distintas armas, unidos por el mismo destino y la misma causa, con la misma gloria "por sus fructíferos desvelos por el bien público" ${ }^{49}$.

\section{Conclusiones}

El análisis de redes permitió establecer que las relaciones matrimoniales condicionaron la escritura de la historia en una coyuntura histórica concreta: la llegada al poder y el gobierno de Manuel María de Iriondo. Algunos de los principales miembros de la Junta de Estudios Históricos, recientemente creada, se abocaron a reconstruir el prestigio de la red de familias en el poder, sobre todo de aquellas familias que sostenían su cohesión. Así se ofreció una visión que

\footnotetext{
${ }^{47}$ Idem, pp. 29, 35 y 36.

${ }^{48}$ Idem, p. 49.

49 Idem, p. 133.
} 
reconciliaba en el pasado a las familias que pretendían dominar en el presente. Uno de los principales argumentos era pertenecer a una genealogía de administradores carismáticos, al mismo tiempo buenos padres y esposos, que habían buscado el orden institucional y el progreso local. La consagración máxima era ser descendiente del brigadier general Estanislao López, el caudillo santafesino, sosteniendo que sus virtudes sociales y políticas fluian en el tiempo consagrando, no sólo a sus parientes directos, sino a los descendientes de sus colaboradores, a su vez emparentados.

\section{Bibliografía}

Balmori, Diana, Voss, S. y Wortman, M. (1990). Las alianzas de familias y la formación del país en América Latina. México: FCE.

Borgatti, Steve (2003). "Conceptos básicos de redes sociales". Analytic Technologies. Social Network Análisis Software. Consulta [5/10/07] en http://www. analytictech.com/networks/introduccion2.pdf

Casasola, Silvia (2003). "El núcleo de la élite colonial de Santiago de Guatemala: un bloque cohesivo", Araucaria, № 10, Sevilla.

Casaús, Marta (1994). “La pervivencia de las redes familiares en la configuración de la elite de poder centroamericana (El caso de la familia Díaz Durán)". Anuario de Estudios Centroamericanos, Vol. 20, № 2, Universidad de Costa Rica.

Cecchini de Dallo, Ana (1992). Los grupos políticos en Santa Fe. Santa Fe: Ministerio de Educación y Cultura de la provincia de Santa Fe.

Falleti, Tulia. y Sislian, F. (1997). Dominación política, redes familiares y clientelismo. Buenos Aires: GEU.

Gori, Gastón (1998). J osé Carmelo Busaniche. Municipalidad de la ciudad de Santa Fe.

Granovetter, Mark (2000). "La fuerza de los vínculos débiles". Revista Política y Sociedad, № 33, Universidad Complutense de Madrid.

Habermas, Jürgen (2000). La constelación postnacional. Ensayos políticos. Barcelona: Paidós.

Herrero López, Reyes (2000). “La terminología del análisis de redes. Problemas de definición y de traducción". Revista Política y Sociedad, № 33, Universidad Complutense de Madrid.

Lozares Colina, Carlos (1996). "La teoría de las redes sociales". Papers, № 48, Universidad Autónoma de Barcelona.

Lozares Colina, Carlos y otros (2003). "Relaciones, redes y discurso: revisión y propuestas en torno en torno al análisis reticular de datos textuales". Reis, № 101, Madrid: Centro de Investigaciones Sociológicas. 
Macor, Darío (2005). Nación y provincia en la crisis de los años treinta. Santa Fe: UNL.

Mann, Michael (1991). Las fuentes del poder social I. Madrid: Alianza.

Piazzesi, Susana (1997). “Después del liberalismo: ¿un nuevo conservadorismo? El Iriondismo santafesino en la década del treinta". Estudios Sociales, № 13. Santa Fe, UNL.

Pizarro, Narciso (2000). “Presentación”. Revista Política y Sociedad, № 33, Universidad Complutense de Madrid.

Quiroga, Águeda (2003). “Introducción al análisis de datos reticulares. Prácticas con UClnet 6 y Netdraw1. Versión 1". Consulta [1/11/07] en http://revistaredes.rediris. es/webredes/

Requena Santos, Félix y Ávila Muñoz, A. (2002). "Redes sociales y sociolingüística". Estudios de Sociolingüística, № 3 (1), Universidad de Vigo.

Rivoir, Ana (1999). "Redes sociales: ¿instrumento metodológico o categoría sociológica?". Revista de Ciencias Sociales, № 15, Montevideo: Universidad de la República y Fundación de Cultura Universitaria.

Rodríguez, Josep y Mérida, F. (s/d). "UCI net 6. Guía práctica de redes sociales". Consulta [1/11/07] en http://www.ub.es/epp/redes/redes.htm

Saguier, Eduardo. Un debate histórico inconcluso en la América Latina (16002000). Cuatro siglos de luchas en el espacio colonial peruano y rioplatense y en la Argentina moderna y contemporánea. Tomo 3. Consulta [5/10/07] en http://www.er-saguier.org

Sanz Menéndez, Luis (2003). “Análisis de Redes Sociales: o cómo representar las estructuras sociales subyacentes". Apuntes de Ciencia y Tecnología, № 7, Asociación para el Avance de la Ciencia y la Tecnología en España.

Tedeschi, Sonia (2007). "Representaciones del pasado argentino en la historiografía santafesina de las décadas de 1930 y 1940. Entre la Historia y la Ciencia Política". Ponencia presentada en el IX Encuentro de Historia Regional Comparada, P.I.H.S.E.R., Santa Fe.

Wellman, Barry (2000). “El análisis estructural: del método y la metáfora a la teoría y a la sustancia". Revista Política y Sociedad, № 33, Universidad Complutense de Madrid.

White, Harrison (2000). "El análisis estructural: del método y la metáfora a la teoría y a la sustancia". Revista Política y Sociedad, № 33, Universidad Complutense de Madrid. 